\title{
The Journal of the Geological Society of India: Challenges that will Confront us in Future
}

\author{
B. Mahabaleswar \\ Geological Society of India, Bengaluru - 560085 \\ E-mail: editorjournalgsi@gmail.com
}

Received: 8 December 2021 / Revised form Accepted: 12 December 2021

(C) 2022 Geological Society of India, Bengaluru, India

The long cherished dream of the founding fathers of the Geological Society of India was that its flagship journal should publish the best work in geology and related fields in the Indian context and from elsewhere as well, has been more than fulfilled. The journal of the Society which started in a modest way continues to appear with unfailing regularity and is eagerly awaited by leading researchers in the field. This by no means a small achievement has been made possible with the active participation of all the Fellows and the Council of the Society in guiding the activities of the Society thereby fulfilling the objectives of the founding fathers.

In tracing the history of the Journal of the Society we can derive certain amount of satisfaction that the development of ideas leading to current understanding of concepts has been a major part of our journey. In all 97 volumes of the journal have now been published with a few Special Issues containing the papers presented at conferences and symposia. Having fulfilled the twin objectives of providing a forum to publish the best among the works, and also providing a platform for leading earth scientists to interact and discuss various geological problems that periodically confronted us, we are now in a position to aim big and confront the challenges that are facing us in the field of publication.

Dr. Harsh Gupta, President of the Geological Society of India, took interest in inviting leading geoscientists of the world to write guest editorials for the journal. These editorials have become a regular feature of the journal. Recently, Prof. Harsh Gupta invited leading Earth Scientists in India and elsewhere to contribute short articles to the journal for faster dissemination of current research topics. This initiative has been received very well and in this issue we have included 11 such articles and we sincerely hope to have more and more submissions in this format.

With the boom in Information Technology and the popularity of internet, there has been increasing demand for information at fingertips. Everyone wants to access the information on the internet thereby creating an insatiable need for online content. In the year 2009, the Geological Society of India collaborated with Springer India to co-publish the journal for the international community. The journal of the Society is now available online to international readership since the year 2009. Simultaneously, the Society, through its own website, is also providing online content of the Journal to its Fellows. All the volumes of the journal have now been digitized and are available online for download.

The field of publication has been changing at a faster rate than what was envisaged. With the advent of digital technology, online publication and print on demand concepts have been sought after. The die-hard fans of reading the journal at leisure are now content with getting the information on i-pads and smart phones. The challenge ahead is to define the scope of online publication keeping abreast with the print publication.

At present, the health of a scientific journal is measured by its H-index, impact factor etc. Despite some reservations about these quantitative metrics, these indices have become a rational and responsible way of evaluation. The Journal impact factor is 1.495 for the year 2020 and we sincerely hope that this increase will be sustained.

A few suggestions have been made that we should publish review articles more often. Review articles summarize recent research results in a novel way which integrate and add to our understanding in a particular field. Methodology papers enumerate the state of the art methods to be implemented for having a comprehensive insight into the problem. Open Access Monographs is another new concept that is emerging and the Geological Society is keen on publishing these monographs on its website.

The Journal of the Society continues to publish Book Reviews, a Correspondence column, Discussion and News and Notes. Suggestions are being made to restrict the News and Notes section to report on major geological findings or an indepth analysis of a geological problem not exceeding two printed pages. The monthly scientific meetings of the Society in hybrid mode has gained momentum in recent years and we encourage all the presenters to submit a detailed not (not 
exceeding two printed pages) for the journal. Discussion section will continue in the present format under Comment and Reply on the articles published earlier in the journal. It is an important aspect of the journal since healthy scientific discussion provides the author about the missing links that has to be considered and also about the alternate interpretations that are possible. I urge our Fellows to use Correspondence column to exchange their view point on the journal and how it can be improved. Recently the journal has got a boost as monthly scientific meetings of the Society in hybrid mode have gained momentum followed by a two page note for the journal.
The last and most important challenge that will confront us in the near future is whether the Geological Society of India should continue to publish the journal or the Journal should become independent on its own with new Editorial autonomy. But for the Geological Society to sustain on its own, the time has come to have a rethink of our strategies and develop a willingness to reorient ourselves in enhancing the visibility of the Journal as well as various activities of the Society. I encourage all the Fellows of the Society to take active part in enrolling members so that the journal and the publications of the Society reaches to all geologists. 